\title{
Behavior of Stannum Segregation to Grain Boundaries in Hot Deformed Non-oriented Silicon Steel
}

\author{
Z.G. AN, H.Y. HOU, C.D. ZHANG, H.J. CUI, L.L. WANG, F. XUE \\ Hebei Iron \& Steel Technology Research Institute, Shijiazhuang, Hebei Province, China
}

\begin{abstract}
Effects of stannum on texture of hot deformed non-oriented electrical steel strip were investigated by using EBSD analysis methods. The stannum segregated to grain boundary in hot deformed non-oriented silicon steel was observed experimentally with transmission electron microscope. The result showed that the texture evolution of hot band was different in different layer during hot deformed process. Stannum segregated to grain boundaries during hot-working process, which leads to decrease of $\{111\}$ texture intensity and increase of $\{100\}$ and $\{110\}$ texture intensity. The magnetic properties of non-oriented silicon steel sheet can be improved obviously by adding trace stannum which segregated at the grain boundary in order to get favorable texture development.
\end{abstract}

KEYWORD: Non-oriented silicon steel; Segregation; Grain boundary; Texture

\section{INTRODUCTION}

Non-oriented silicon steel is one of important soft magnetic materials in power, machinery and electronic industries. It's designed and produced aiming to reduce the power losses and to increase the permeability. The texture will affect the microstructure dependent magnetic properties of the steel, mainly the power losses and permeability. Formation of (100) texture in non-oriented silicon steel sheets and an increase of grain size are hopeful ways to develop magnetic properties. [1]

Previous papers have reported that the addition of trace stannum, antimony and other elements in the non-oriented silicon steel, which due to the grain boundary segregation, can help to improve its favorable texture and the magnetic induction intensity.[2] But the addition amount of trace stannum and/or antimony exceeds the range, the iron loss and magnetic properties have deteriorated. In this paper, we report changes in hot deformed texture and microstructure of non-oriented silicon steel due to different contents of Stannum.

\section{EXPERIMENTAL PROCEDURE}

Experimental steels were melted in a $50 \mathrm{~kg}$ vacuum induction furnace and their chemical compositions were shown in Table 1. In contrast, steel A does not have stannum added. The cast ingots were directly forged into plates of $30 \mathrm{~mm}$ thickness. The plates were hot rolled on a laboratory mill in six passes to a thickness of $2.4 \mathrm{~mm}$. The finishing rolling temperature was $860^{\circ} \mathrm{C}$.

Table 1. Chemical composition of experimental steels (mass fraction, \%).

\begin{tabular}{|c|c|c|c|c|c|c|c|}
\hline Samples & $\mathrm{C}$ & $\mathrm{Si}$ & $\mathrm{Mn}$ & $\mathrm{Al}$ & $\mathrm{S}$ & $\mathrm{P}$ & $\mathrm{Sn}$ \\
\hline Steel A & 0.0027 & 2.77 & 0.23 & 0.45 & 0.0040 & 0.007 & -- \\
\hline Steel B & 0.0020 & 2.74 & 0.24 & 0.43 & 0.0031 & 0.008 & 0.036 \\
\hline Steel C & 0.0024 & 2.72 & 0.27 & 0.42 & 0.0035 & 0.007 & 0.064 \\
\hline
\end{tabular}

The microstructure and micro-texture of hot deformed bands with these different stannum contents were investigated by using electron backscattered spectroscopy (EBSD) in the ZEISS ULTRA 55 FEG SEM. The stannum segregated to grain boundary in hot deformed non-oriented silicon steel was examined using a FEI Tecnai G2 F30 scanning transmission electron microscope, operating at $300 \mathrm{kV}$ and the associated EDA analytical facility.

\section{RESULTS}

Figure 1 shows the microstructures of the specimens after hot deformed. It can be seen that the subsurface and central area of the specimen containing no stannum remains unrecrystallized and shows a 
deformed microstructure, the surface area microstructures of the hot deformed band for steel A are equiaxed ferrite grains (Fig.1a). For steel B, the subsurface and central area of the specimen containing $0.036 \mathrm{wt} \%$ stannum shows a small amount of incomplete recrystallization grains (Fig.1b). However, when the stannum content is $0.064 \mathrm{wt} \%$ for steel $\mathrm{C}$, the complete recrystallization throughout the thickness has occurred (Fig.1c). Although there exists a large scattering in the recrystallized grains in hot- deformed specimens, it is found that the overall grain size seems to decrease as the stannum content increases.

The microtextures of hot deformed bands observed by EBSD are shown in Fig. 1. Here, blue grains represent $\{111\}$ and green grains represent $\{001\}$ orientation. Red grains represent Goss orientation. White grains are considered as having random orientation. It can be seen that the three hotrolled plates containing different $\mathrm{Sn}$ are present $\{111\}$ orientation, $\{001\}$ orientation and Goss orientation component, but these texture component content and distribution are differences.

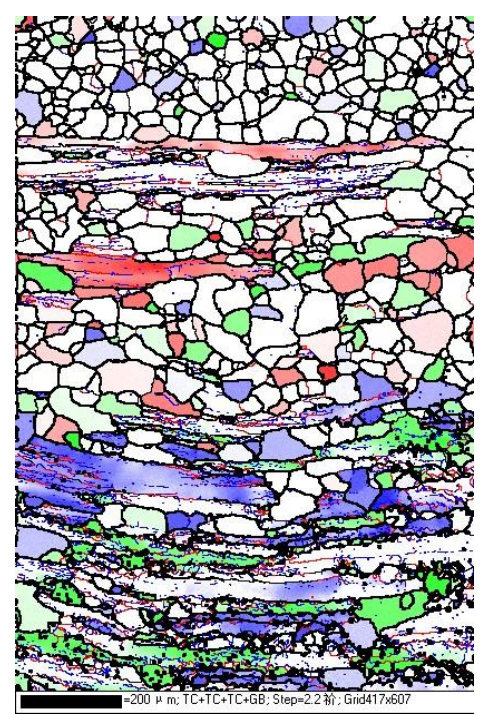

(a)

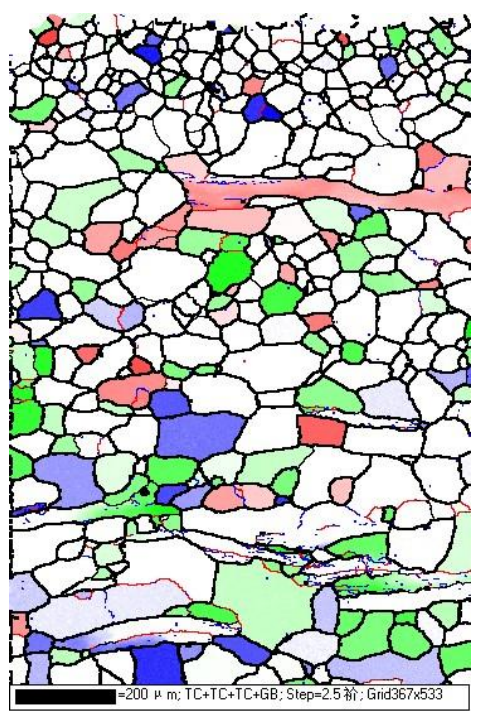

(b)

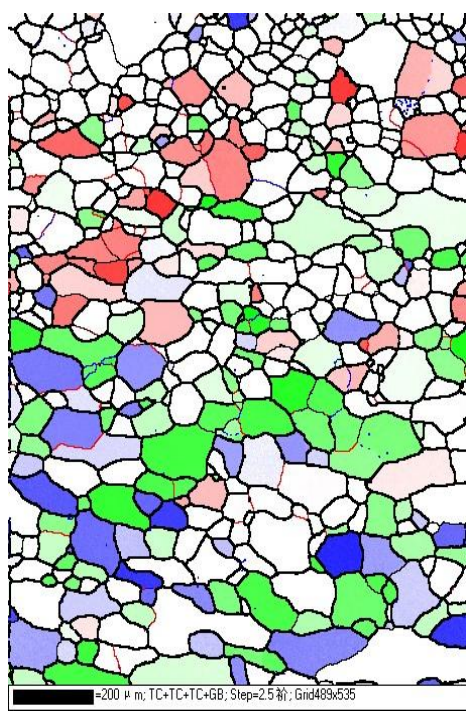

(c)

Figure1. EBSD analysis of hot deformed bands for experimental steels (a) steel A; (b) steel B; (c) steel C.

As for steel A containing no stannum, the $\{111\}$ texture component of hot-deformed plate is the strongest, followed by $\{001\}$ texture component which represented by green grains, but the Goss oriented component is weak (Fig. 1a). The $\{111\}$ grain orientation is significantly reduced in steel B which $0.036 \mathrm{wt} \%$ stannum was added, in comparison with steel A (Fig.1b). In Figure 1 (c), $\{111\}$ grain orientation in steel C containing $0.064 \mathrm{wt} \%$ stannum, is further reduced, and $\{001\}$ orientation and Goss orientation increased which is beneficial to the magnetic properties. Therefore, the addition of stannum in non-oriented silicon steel can effectively restrain the $\gamma$ texture growth and promote the growth of cube texture and Goss texture during hot deformation process.

Stannum is a typical grain boundary segregation element, which easily segregates to grain boundaries during hot deformation and annealing process, thus affecting the microstructure and mechanical properties of materials. The hot deformed microstructures and EDS spectrum of grain boundary for experimental steels observed by STEM and are shown in Figure 2.
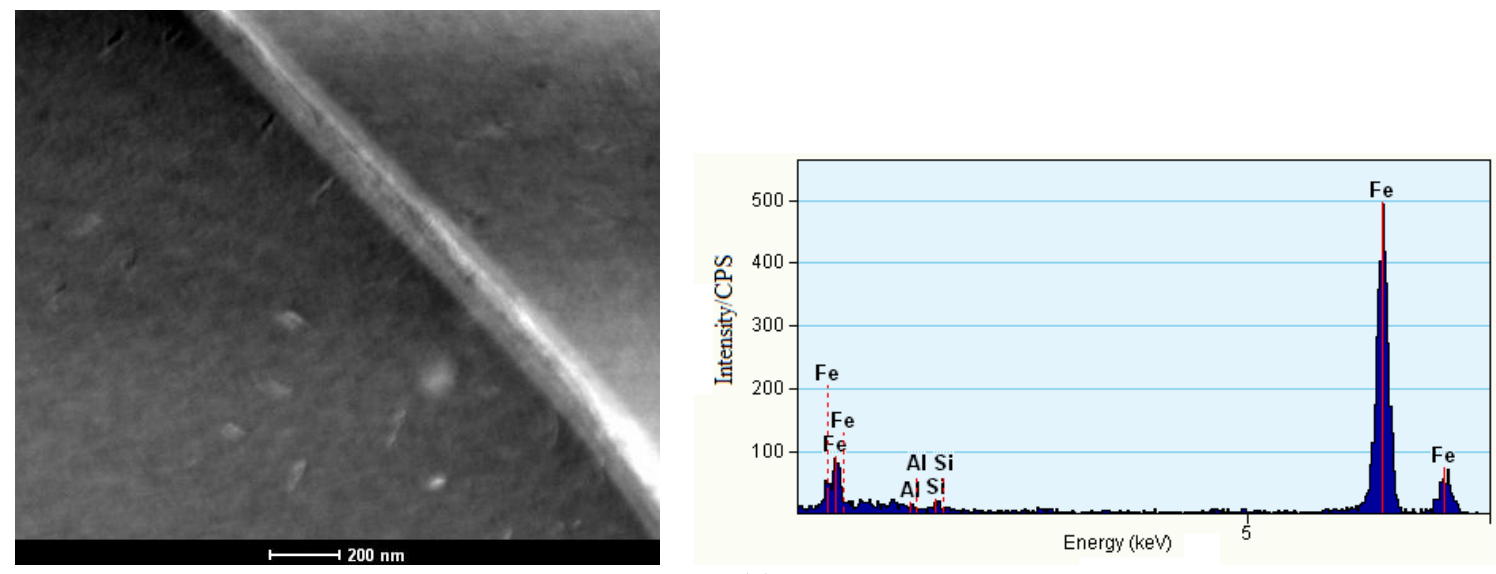

(a) 

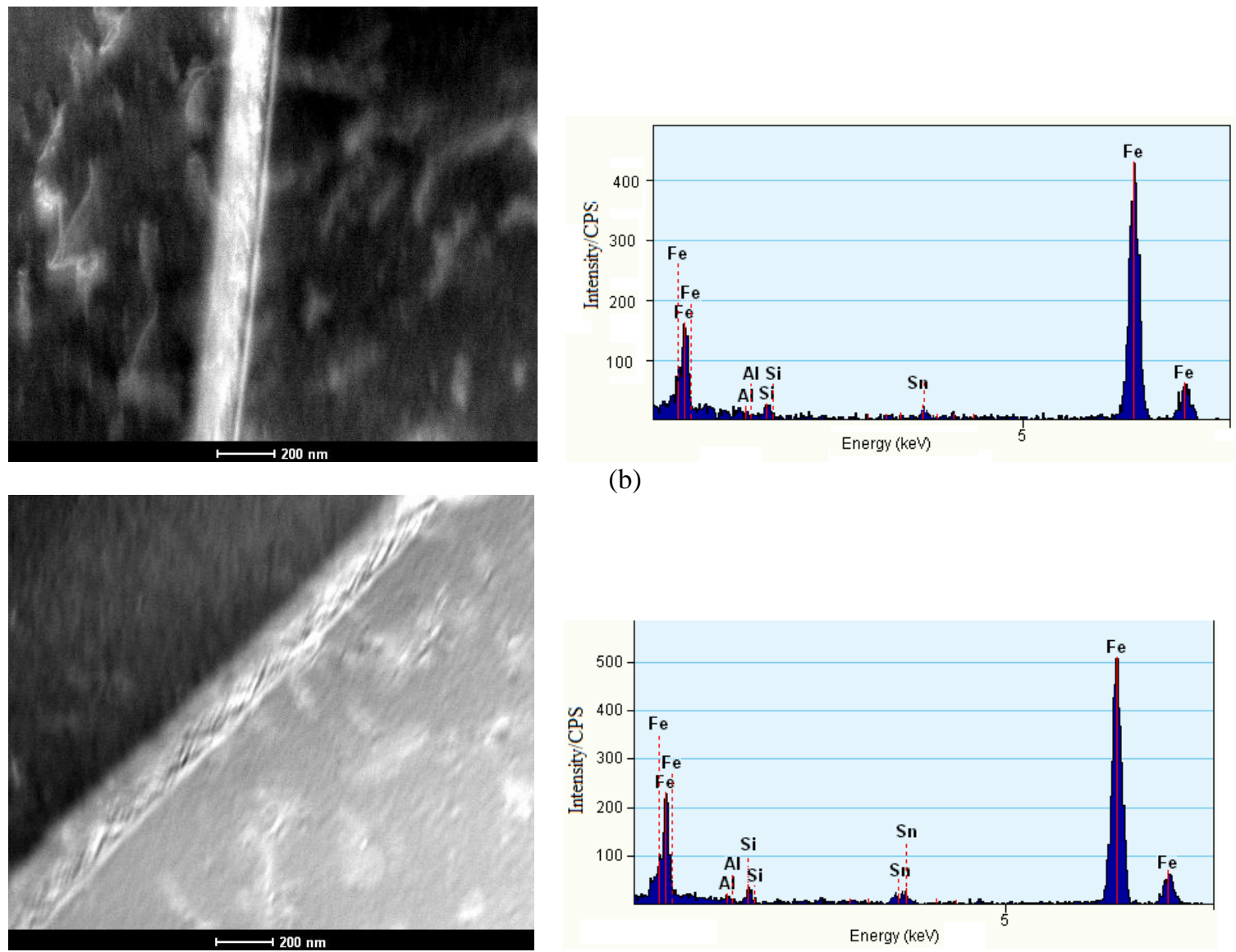

(b)

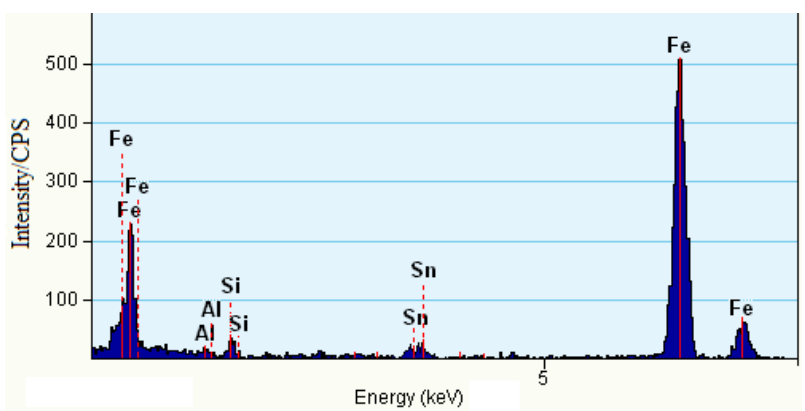

(c)

Figure 2. STEM micrographs and EDS spectrum of grain boundary (a) steel A; (b) steel B; (c) steel C.

The EDS spectrum quantitative analysis of grain boundary for hot deformed steel A shows that stannum peak was not found (Fig.2a). But the $0.76 \mathrm{wt} \%$ stannum was found on the ferrite grain boundary of steel B containing $0.036 \mathrm{wt} \%$ stannum(Fig.2b). For steel C, the stannum content on the grain boundary increases to $1.87 \mathrm{wt} \%$ (Fig.2c). Thus, adding small amount of stannum for non oriented silicon steel, can obviously segregation on the grain boundaries. Therefore, it can be concluded that stannum segregates on grain boundaries and the amount of segregation becomes larger as its content increases.

\section{DISCUSSION}

In the segregation processes, the isothermal kinetic $r$ elationship for non-equilibrium grain-boundary segregation is given in as [3]

$$
\begin{aligned}
& C_{b}(t)=C_{g}+\frac{1}{2}\left[C_{b}\left(t_{c}\right)-C_{g}\right] \times \\
& \left\{\operatorname{erf} \frac{d}{2\left[4 D_{t}\left(t-t_{c}\right)\right]^{1 / 2}}-\operatorname{erf} \frac{-d}{2\left[4 D_{i}\left(t-t_{c}\right)\right]^{1 / 2}}\right\}
\end{aligned}
$$

Where $C_{b}(t)$, of the solute atoms on the grain boundary as a function of the isothermal holding time $t$ at the constant temperature when $\mathrm{t}$ is shorter than the critical time $t_{c}\left(t<t_{c}\right) . C_{b}\left(t_{c}\right)$ is the maximum concentration (supposing that the sample is cooled quickly from temperature $T$ down to $T_{c}$ ), $D_{t}$ is the diffusion coefficient of complexes, [4] $D_{t}=5 \times 10^{-5} \times \exp (-1.6 / K T) \quad \mathrm{m}^{2} / \mathrm{s} . \quad D_{i}$ is the diffusion coefficient of stannum, [5] $D_{i}=1.65 \times 10^{-5} \times \exp (-2 / K T) \quad \mathrm{m} 2 / \mathrm{s} . \quad C_{g} \quad$ is the concentration of solute atoms within the grain, $d$ is the average grain size. Boltzmann constant $K=8.617 \times 10^{-5} \mathrm{eV} / \mathrm{K}$.

In the present study, the grain boundary segregation stannum amount of three kinds experimental steels calculated as shown in Table 2:

Table 2. Grain boundary concentrations of stannum in experimental steels.

\begin{tabular}{|c|c|c|c|}
\hline Steel & Steel A & Steel B & Steel C \\
\hline Stannum, wt\%, measured value & 0 & 0.76 & 1.87 \\
\hline Stannu, wt\%, calculated value & 0 & 0.85 & 2.08 \\
\hline
\end{tabular}

Consideration the test error and approximation calculation, Table 2 indicated the results which use non-equilibrium grain boundary segregation theory to calculate are probably consistent with the results of the EDS spectrum quantitative analysis.

The grain boundary segregation is so termed because the solute atoms segregate themselves to the grain boundaries in accordance with the statistics of 
thermodynamics in order to minimize the overall free energy of the system.[6] Because the grain boundary segregation, the content of stannum on the grain boundary is significantly higher than within grain. Grain boundary migration attempts to drag stannum atoms move together, but the moving speed of stannum atoms which are on grain boundary and follow the grain boundary is limited by its diffusion velocity in the matrix, which lead to the grain boundary migration was towed by a drag force. Therefore, the moving speed of the grain boundary is greatly reduced, which is a obstacle to recrystallization and grain growth.

During recrystallization process of non-oriented silicon steel, the grain boundary energy reduction will inhibit certain texture components which are easily nucleated and grew at the original formed grain boundary, The $\{111\}$ textures are more easily nucleated at initial grain boundaries.[7] Grain boundary segregation of stannum directly affects the $\{111\}$ component of the nucleation and grain growth. Thus the $\{111\}$ component strength of nonoriented silicon steel hot deformed plates is greatly reduced, while the proportion of $\{110\}$ texture and $\{001\}$ texture components are increased (Fig.1).These are beneficial to the improvement of the magnetic properties.

\section{CONCLUSIONS}

The behaviors of stannum segregation to grain boundaries in hot deformed non-oriented silicon steel have been investigated. The following results were obtained.

(1) The stannum segregated to grain boundaries of non-oriented silicon steel, which has affected recrystallization grains nucleation and growth during hot deformed process. This is the reason why the hot deformed texture and microstructure can be improved by adding trace stannum in the nonoriented silicon steel.

(2) With increasing stannum content in nonoriented silicon steel, it directly affects on the $\{111\}$ grain nucleation and growth during hot deformed process. The $\gamma$ texture is weakened, the cube texture and Goss texture components are strengthened in hot deformed plates of non-oriented silicon steel.

\section{ACKNOWLEDGEMENT}

This research was financially supported by the Natural Science Foundation - Steel and Iron Foundation of Hebei Province (No.E2012318002).

\section{REFERENCES}

[1] Wang,B. 2004.Development of low silicon non-oriented electrical steel for high-efficiency cores. Metallic Functional Materials 11(2):24-29.

[2] Kubota T.2005.Recent progress on non-oriented silicon steel. Steel Research International 7(66):464-469.

[3] Xu T.D. \& Song S.H.1989.A kinetic model of nonequilibrium grain boundary segregation. Acta Metallurgica 37:2499-2503.

[4] Bowen A.W. \& Lesk G.M. 1970. Diffusion in Bcc iron base alloys. Metall Trans (1):2769-2771.

[5] Jia J. \& Shi H.Y. \& Yuan Z.X.2004. Determination of critical time of non-equilibrium segregation of Tin. Journal of Wuhan University of science and technology 27(3):230233.

[6] Park J.T. \& Woo J.S. \& Chang S.K.1998. Effect of phosphorus on the magnetic properties of non-oriented electrical steel containing $0.8 \mathrm{wt} \%$ silicon. Journal of Magnetism and Magnetic Materials 182:381-388.

[7] Rubens T. \& Fernando J.G.L.2006. Effect of hot-band grain size and intermediate annealing on magnetic properties and texture of non-oriented silicon steels. Journal of Magnetism and Magnetic Materials 304:608610. 